\title{
Surface Complexation of Actinides with Iron Oxides: Implications for Radionuclide Transport in Near-Surface Aquifers
}

\author{
James L. Jerden Jr., A. Jeremy Kropf and Yifen Tsai \\ Argonne National Laboratory, 9700 South Cass Avenue, Argonne, IL 60439
}

The surface complexation of actinides with iron oxides plays a key role in actinide transport and retardation in geosphere-biosphere systems. The development of accurate actinide transport models therefore requires a mechanistic understanding of surface complexation reactions (i.e. knowledge of chemical speciation at mineral/fluid interfaces). Iron oxides are particularly important actinide sorbents due to their $\mathrm{pH}$ dependent surface charges, relatively high surface areas and ubiquity in oxic and suboxic near-surface systems. In this paper we present results from field and laboratory investigations that elucidate the mechanisms involved in binding uranium and neptunium to iron oxide mineral substrates in near neutral groundwaters. The field study involved sampling and characterizing uranium-bearing groundwaters and solids from a saprolite aquifer overlying an unmined uranium deposit in the Virginia Piedmont. The groundwaters were analyzed by inductively coupled mass spectrometry and ion chromatography and the aquifer solids were analyzed by electron microprobe. The laboratory study involved a series of batch sorption tests in which $U(V I)$ and $N p(V)$ were reacted with goethite, hematite and magnetite in simulated groundwaters. The $\mathrm{pH}$, ionic strength, aging time, and sorbent/sorbate ratios were varied in these experiments. The oxidation state and coordination environment of neptunium in solutions and sorbents from the batch tests were characterized by X-ray absorption spectroscopy (XAS) at the Advanced Photon Source, Argonne National Laboratory. Results from this work indicate that, in oxidizing near-surface aquifers, the dissolved concentration of uranium may be limited to less than 30 parts per billion due to uptake by iron oxide mineral coatings and the precipitation of sparingly soluble $\mathrm{U}(\mathrm{VI})$ phosphate minerals. Results from the batch adsorption tests showed that, in near neutral groundwaters, a significant fraction of the uranium and neptunium adsorbed as strongly bound surface complexes that were not removed (desorbed) when the sorbents were resuspended in dilute groundwater. The XAS results indicate that at $\mathrm{pH} 7.0-8.0$ neptunium adsorbs to goethite as a neptunyl(V) complex and to magnetite as an inner-sphere $\mathrm{Np}$ (IV) complex with a $\mathrm{Np}$ - Fe distance of approximately 3.5 angstroms. These findings demonstrate that the presence of iron oxides in oxidizing near-surface aquifers may significantly retard actinide transport and that future reactive-transport models for actinides should therefore account for irreversible sorption processes. 